\title{
An Improved Method of Percutaneous Transhepatic Biliary Drainage Combining Ultrasound-Guided Bile Duct Puncture with Metal Stent Implantation by Fluoroscopic Guidance and Endoscopic Visualization as a One-Step Procedure: A Retrospective Cohort Study
}

\author{
Daniel Schmitz ${ }^{1}$ Niels Weller ${ }^{1} \quad$ Matthias Doll ${ }^{1} \quad$ Simon Weingärtner ${ }^{1} \quad$ Nuria Pelaez \\ Gabriele Reinmuth ${ }^{1}$ Svetlana Hetjens ${ }^{2}$ Jochen Rudi ${ }^{1}$
}

\footnotetext{
${ }^{1}$ Department of Gastroenterology, Oncology and Diabetology, Tertiary Referral Hospital, Theresienkrankenhaus und St. Hedwig Hospital, Academic Teaching Hospital of Heidelberg University, Mannheim, Germany

${ }^{2}$ Department of Medical Statistics, Biomathmatics and Information Processing of Mannheim University Hospital, Heidelberg

University-Hospital, Mannheim, Germany
}

\begin{abstract}
Address for correspondence Daniel Schmitz, MD, Department of Gastroenterology, Oncology and Diabetology, Theresienkrankenhaus und St. Hedwig Hospital, Academic Teaching Hospital of Heidelberg University, Bassermannstr.1, 68165 Mannheim, Germany (e-mail: d.schmitz@theresienkrankenhaus.de).
\end{abstract}

J Clin Interv Radiol ISVIR 2018;2:135-143

\begin{abstract}
Aims In recently published comparative studies, it is reported that percutaneous transhepatic biliary drainage (PTBD) is less successful, causes more adverse events, and needs more re-interventions than endoscopic ultrasound-guided biliary drainage (EUS-BD) in patients with malignant extrahepatic bile duct obstruction when endoscopic retrograde cholangiopancreatography (ERCP) fails. Could an improved technique of PTBD produce better results to use this technique for further comparative studies with EUSBD?

Methods In our tertiary referral hospital, 116 prospectively documented, and retrospectively analyzed PTBDs with ultrasound guided ductal puncture were performed. In 16 of 30 PTBDs with metal stent implantation in malignant diseases, metal stent was inserted as a one-step procedure by endoscopic luminal guidance in the first session. Results Fifteen of $16(94 \%)$ or $14 / 16(88 \%)$ of PTBDs with primary metal stent implantation were technically or clinically successful. Mainly the left liver was used as access route for PTBD. Procedure time was 68.1 minutes (25-118), fluoroscopic time: 18.6 minutes (3-46), and patient radiation exposure: $5957 \mu \mathrm{Gy} / \mathrm{m}^{2}(471-17,569)$. In 2/16

Keywords

- malignant extrahepatic bile duct obstruction

- percutaneous transhepatic biliary drainage

- ultrasound-guided bile duct puncture (12.5\%) patients, adverse events $(1 \times$ mild and $1 \times$ moderate grade of severity) were documented. One re-intervention was necessary $(0.1 /$ patient) in the observation time of 6 months. The mean overall survival time was 163.2 (7-864) days after PTBD.

Conclusions PTBD with ultrasound-guided ductal puncture and primary metal implantation by endoscopic luminal guidance in patients with malignant extrahepatic bile duct obstruction showed good technical and clinical success and low adverse event and reintervention rates in our retrospective cohort study.

Clinical Trial Registration: ClinicalTrials.gov ID: NCT03541590.
\end{abstract}

received

June 29, 2018

accepted after revision

August 1, 2018

published online

November 27, 2018
DOI https://doi.org/

$10.1055 / \mathrm{s}-0038-1675883$

ISSN 2457-0214.
C2018 by Indian Society of

Vascular and Interventional

Radiology
License terms

(c) $9 \$$ 


\section{Introduction}

Endoscopic drainage or stenting is the method of first choice in the therapy of malignant bile duct obstruction in comparison with percutaneous transhepatic biliary drainage (PTBD) ever since the study from Speer et al showed a significantly higher success rate for relief of jaundice ( $81 \%$ versus $61 \%$ ) and a significantly lower 30 -day mortality rate (15\% versus $33 \%$ ) in 1987. ${ }^{1}$ From then on, PTBD was commonly used as a reserve method when endoscopic drainage or stenting was not successful or otherwise was not possible for anatomic reasons after abdominal surgery. Endoscopic ultrasound-guided biliary drainage (EUS-BD) was first described in 2001 by Giovannini et $\mathrm{al}^{2}$ and is now a rapidly evolving method for biliary drainage in patients with malignant bile duct obstruction in this setting. A recent meta-analysis about efficacy and safety in EUS-BD in comparison with PTBD included six completely published studies ${ }^{3-8}$ and three abstracts with 483 patients and showed better clinical success, fewer post-procedural adverse events, and a lower rate of re-interventions for EUS-BD. ${ }^{9}$ The authors concluded that EUS-BD may be preferred to PTBD if adequate endoscopic expertise and logistics are available. The question is rather-was the full potential of PTBD exploited in these studies when it was compared with the different procedures of EUS-BD?

Percutaneous transhepatic biliary drainage is usually performed under fluoroscopic guidance in which the initial puncture of the intrahepatic bile duct is performed with the help of anatomic landmarks without a direct view of the bile duct. ${ }^{10}$ Color Doppler ultrasound-guided PTBD facilitates bile duct access, and injury of intrahepatic vessels can be avoided more effectively. ${ }^{11-15}$ External percutaneous drainages can both cause bad patient comfort and pain and carry the risk of dislocation and other adverse events. ${ }^{16}$ Therefore, external drainages should be avoided. Furthermore, success and complications of PTBD are influenced by the liver entry segment. ${ }^{17}$ Hence, the left-sided liver access should be preferred whenever possible. In patients with malignant bile duct obstruction, a metal stent implantation can be performed via PTBD as an effective palliative treatment. ${ }^{18}$ In our institution, the placement of the self-expandable metal stent is always controlled by endoscopic luminal guidance when the papilla is still accessible endoscopically. Therefore, technical success can be documented immediately, no external drainage has to be left behind, and it may be easier to perform endoscopic re-interventions in case of an occluded metal stent. In what follows, we retrospectively screened all prospectively documented PTBDs that were performed in our institution in the last 9 years. We extracted these ultrasound-guided PTBDs, which were performed in patients with malignant bile duct obstruction with primary metal stent implantation by endoscopic luminal guidance as a one step-procedure (mainly with left sided liver access). In this cohort, the technical and clinical success of metal stent implantation via PTBD, adverse events, and re-intervention rate as the follow-up after stent implantation were analyzed.

\section{Patients and Methods}

\section{Patients}

The study (NCT03541590) was reviewed and approved by the local institutional review board. Data collection was performed prospectively according to the updated 2013 World Medical Association (WMA) Declaration of Helsinki. ${ }^{19}$ Patients were not required to give informed consent to the study because the analysis used anonymous clinical data that were obtained after each patient agreed to treatment by written consent. Analysis of the data was performed retrospectively. A total of 116 color Doppler ultrasound-guided PTBD procedures in patients with benign and malign bile duct obstruction were enrolled consecutively in the study from December 2008 to May 2018. Patient selection is shown in a flow chart ( - Fig. 1). Thirty color Doppler ultrasound-guided PTBDs in patients with inoperable, malignant diseases with primary (i.e., inserted in the first session) and secondary (i.e., inserted in a follow up session) metal stent implantation

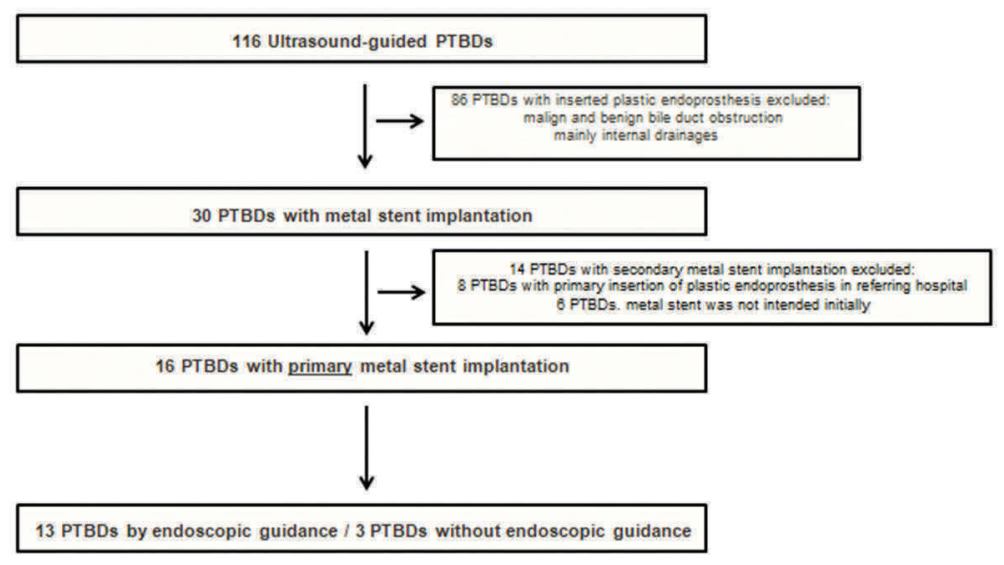

Fig. 1 Flow chart summarizing patient selection process. PTBD, percutaneous transhepatic biliary drainage. 
were extracted from this cohort of participants. In 86 excluded PTBDs, plastic endoprosthesis (mainly internal drainages) was inserted for different reasons. Out of 14 PTBDs with secondary metal stent implantation, 8 patients received PTBD with primary plastic endoprosthesis in referring hospitals, and in 6 patients, metal stent implantation was not intended initially. Sixteen patients with primary metal stent implantation met the following criteria for inclusion and exclusion-inclusion criteria: age $\geq 18$ years, not curatively operable, malignant disease with proximal or distal bile duct obstruction, elevated serum bilirubin level and/or elevated alkaline phosphatase to at least a two-fold degree, histologically verified diagnosis (for example by biopsy), and at least one implemented cross-sectional imaging method, such as computed tomography or magnetic resonance imaging of the abdomen and exclusion criteria: uncorrectable coagulopathy (prothrombin time $<50 \%$, platelet count $<50.000 / \mu \mathrm{L}$, and partial thromboplastin time (PTT) $>50 \mathrm{~s}$ ), advanced tumor disease with limited life expectancy ( $<1$ month), diffuse liver metastasis, pregnant or breastfeeding women, potentially curatively, operable, malignant bile duct obstruction, and diseases which can be cured by chemotherapy (for example, aggressive non-Hodgkin lymphoma).

\section{Methods}

When endoscopic retrograde cholangiopancreatography (ERCP) failed due to tumor stenosis or a difficult papilla or was otherwise anatomically impossible (altered anatomy after abdominal surgery), PTBD was performed next in all patients. PTBD with initial color Doppler ultrasound-guided bile duct puncture was conducted, as previously described. ${ }^{15}$ Left-sided liver access was preferred ( - Fig. 2). After the guide wire was placed beyond the tumor stenosis, a second investigator introduced a standard (outer diameter of the distal

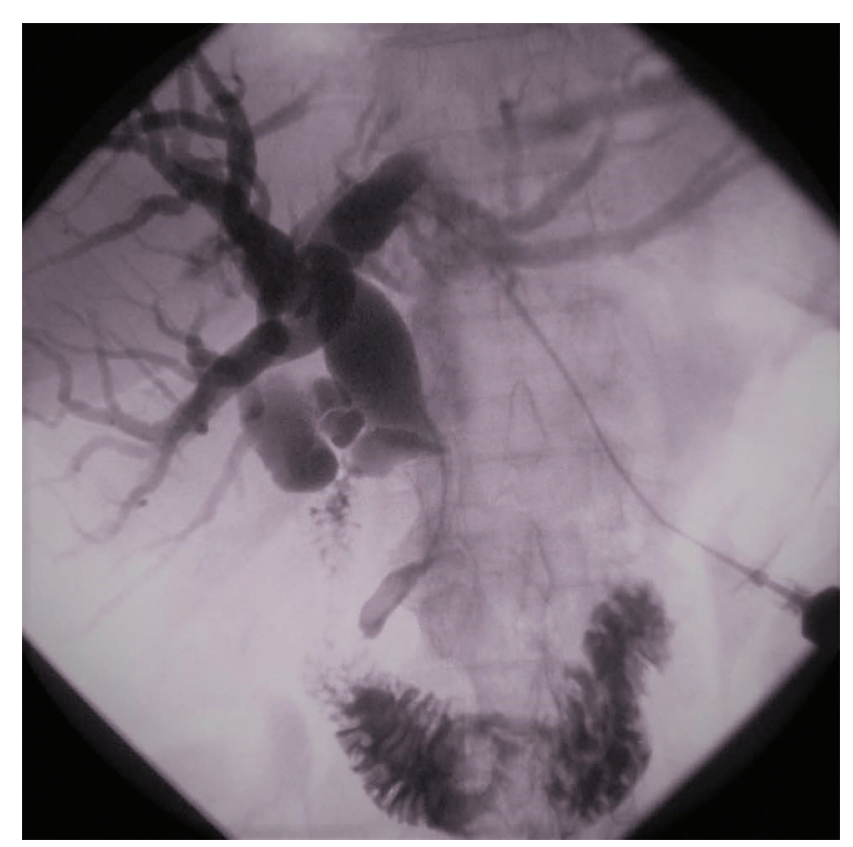

Fig. 2 Fluoroscopic image of PTBD with left sided liver access. PTBD, percutaneous transhepatic biliary drainage. end: $9.9 \mathrm{~mm}$ ) gastrointestinal videoscope (GASTROINTESTINAL VIDEOSCOPE GIF-HQ190, Olympus) or a thin (outer diameter of the distal end: $5.4 \mathrm{~mm}$ ) pediatric gastrointestinal videoscope (GASTROINTESTINAL VIDEOSCOPE GIF-HQ190) into the duodenum passing the tumor stenosis. Then an uncovered or partially covered $(8-10 \mathrm{~mm} \times 60-100 \mathrm{~mm}$ ) self-expandable metal stent (SEMS) (Boston Scientific; Endoflex) was percutaneously inserted by fluoroscopic ( - Fig. 3) and endoscopic luminal guidance ( - Fig. 4 ) in the same session. In contrast, a duodenovideoscope (VIDEODUODENOSCOPE TJF-Q180V, Olympus) with a larger diameter (13.7 mm) and a less flexible distal end could not be introduced to the papilla in all patients with duodenal tumor obstruction. Only in three patients with tumor recurrence at the biliodigestive anastomosis or status post gastrectomy, stent release was performed without endoscopic luminal guidance ( - Fig. 5).

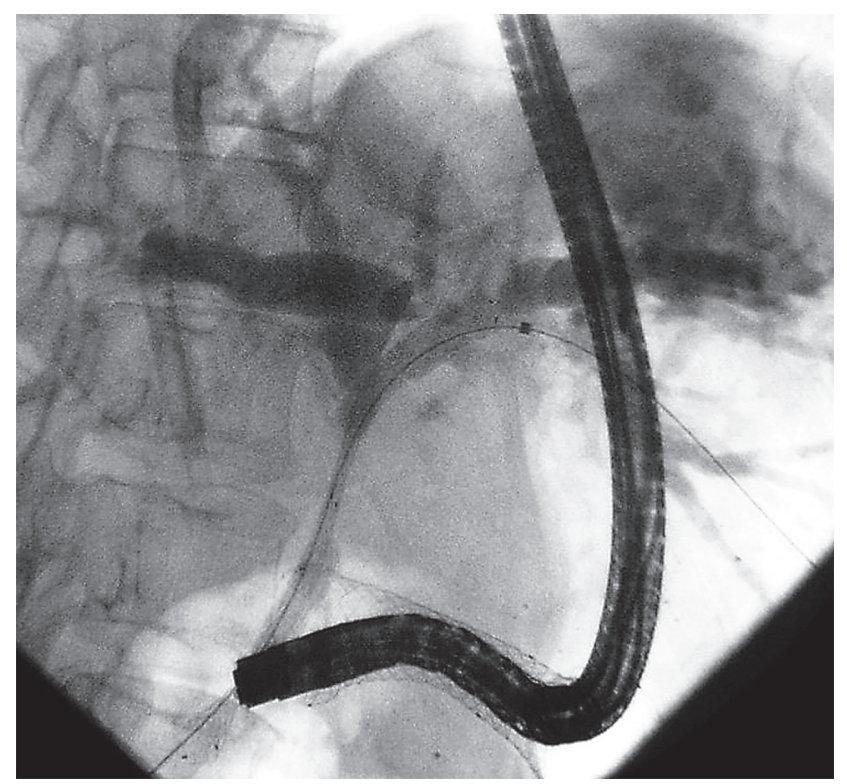

Fig. 3 Percutaneous transhepatic metal stent implantation by endoscopic luminal guidance (fluoroscopic image). The endoscope was introduced through a previously implanted duodenal metal stent.

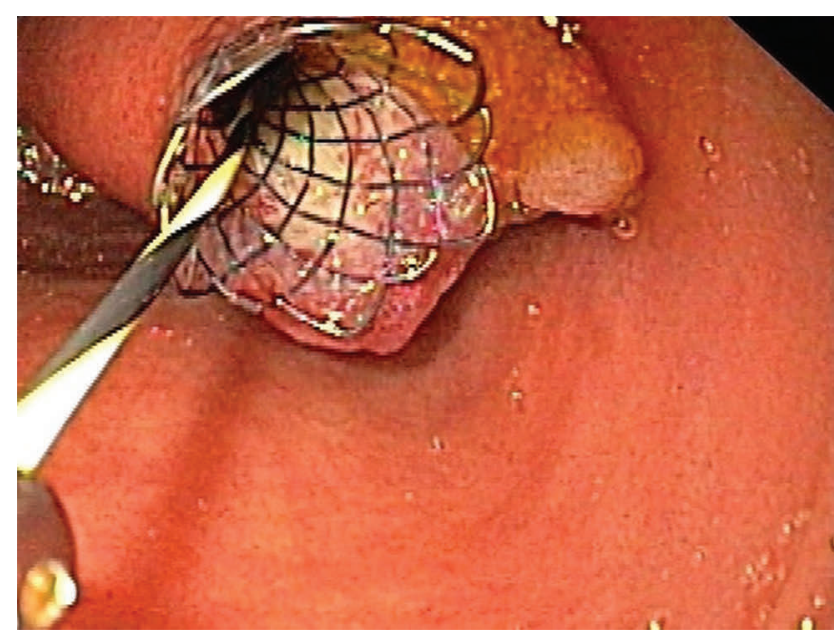

Fig. 4 Percutaneous transhepatic metal stent implantation by endoscopic luminal guidance (endoscopic image). 


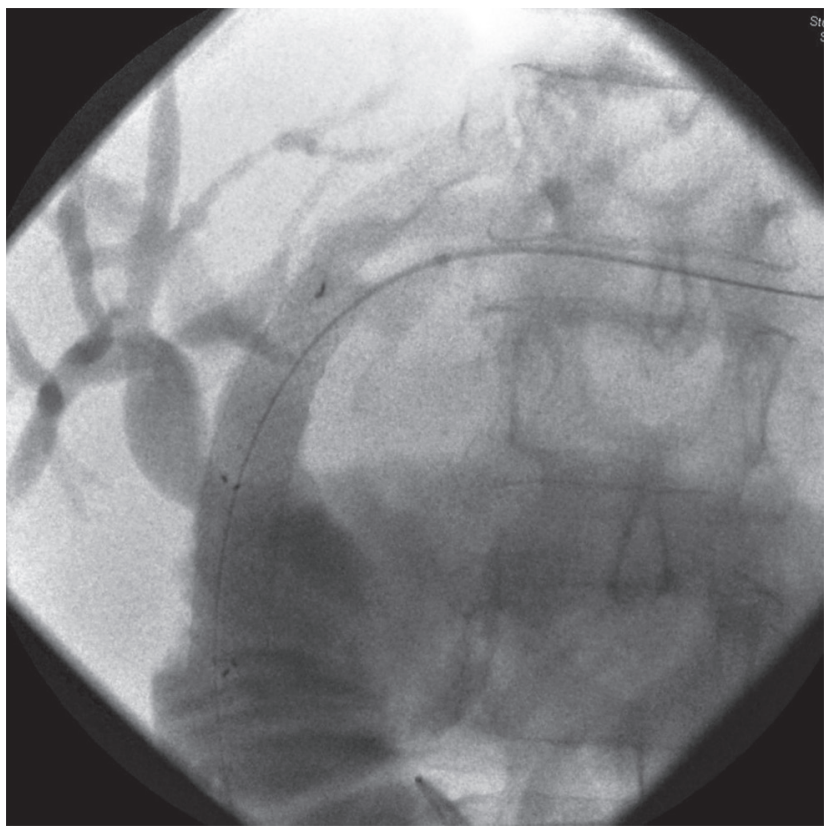

Fig. 5 Percutaneous transhepatic metal stent implantation without endoscopic luminal guidance in a 66-year-old patient with tumor recurrence at the biliodigestive anastomosis (fluoroscopic image).

Successful placement and unfolding of the SEMS was furthermore documented by contrast medium injection through a newly inserted $5 \mathrm{~F}$ catheter. After successful SEMS implantation, the percutaneous catheter and the guide wire were completely removed.

\section{Analysis of Data}

Selected patients were characterized by age, sex, the reason for impossible or unsuccessful ERCP, and the underlying inoperable malignant disease.

The color Doppler ultrasound-guided PTBD procedure was characterized by liver access side (left/right), utilized SEMS (diameter, length in $\mathrm{mm}$, non-covered ( $\mathrm{nc}$ ) or partially covered (pc), applied endoscopic control (yes/no), procedural time (defined as the time from the injected local anesthesia to the attachment of the skin patch), applied radiation exposure for the patient $\left(\mu \mathrm{Gy} / \mathrm{m}^{2}\right)$, fluoroscopic time in minutes, and technical success. Technical success was defined as successful implantation of a self-expanding metal stent to drain the obstructed bile duct, measured by the successful drainage of the radiocontrast agent by the metal stent; time frame: 1 minute after injection of a radiocontrast agent into the expanded metal stent.

The outcome of the PTBD was characterized by clinical success (defined as the decrease of serum bilirubin level $\geq 50 \%$ in comparison with the baseline level after 7 days), the report of any adverse events in the period of 7 days after the procedure, grading of adverse events according to the ASGE lexicon's severity grading system, ${ }^{20}$ and the occurrence of adverse events and number of re-interventions in the period of 6 months after the technical successful intervention.

The follow-up after PTBD was characterized by received chemotherapy (yes or no, chemotherapy protocol), survival time in days, and cause of death (primary disease, other causes). A Kaplan-Meier analysis was performed to estimate patient survival (program SAS 9.3).

\section{Results}

During the study period, 116 PTBDs were performed. Sixteen patients (mean age: 72 years and number of females: 7) with malignant biliary obstruction underwent color Doppler ultrasound-guided PTBD with primary metal stent implantation. ERCP was not successful or was impossible by duodenal tumor stenosis $(n=9)$, biliodigestive anastomosis after pancreaticoduodenectomy $(n=2)$, gastric outlet obstruction by tumor $(n=1)$, status post gastrectomy $(n=2)$, hilar cholangiocarcinoma $(n=1)$, or difficult papilla by tumor infiltration $(n=1)$. Malignant biliary obstruction was mainly caused by pancreas carcinoma $(n=10)$, hilar or distal cholangiocarcinoma $(n=2)$, duodenal carcinoma $(n=2)$, carcinoma of the duodenal papilla $(n=1)$, or gastric cancer $(n=1)$ (-Table 1).

Percutaneous transhepatic biliary drainage with primary metal stent implantation was mainly performed by endoscopic luminal guidance (13/16). In three patients, endoscopic luminal guidance was not possible due to altered anatomy (biliodigestive anastomosis or status post gastrectomy). Left liver side was mainly used as access route (14/16). The metal stent that was used most had a diameter of $10 \mathrm{~mm}$ and a length of $80 \mathrm{~mm}$. Procedure time was on average 68.1 minutes (25-118), fluoroscopic time was on average 18.6 minutes (3-46), and the radiation exposure was on average $5957 \mu \mathrm{Gy} / \mathrm{m}^{2}$ (471-17,569). The intervention was technically successful in $94 \%$ of cases $(15 / 16)$. In one patient, a second attempt was necessary (documented as re-intervention) (-Table 2 ).

Clinical success could be documented in $88 \%$ of cases $(14 / 16)$. In one patient with a tumor stenosis at the biliodigestive anastomosis, in which the first metal stent migrated (patient no. 11), a second metal stent could be inserted at the correct position (grade of severity: mild). Another patient (patient no. 15) developed biliary ascites after a technically successful stent implantation due to delayed stent expansion. The delay was caused by diffuse tumor infiltration and by a duodenal metal stent in direct vicinity to the inserted biliary stent ( - Fig. 6). Hospital stay was prolonged in this patient for 9 days due to several abdominal paracenteses (grade of severity: modest). In the follow-up period of 6 months, just one re-intervention and no stent occlusion could be documented.

Four patients received palliative chemotherapy after normalization of serum bilirubin levels. Survival time extended from 7 to 864 days. A Kaplan-Meier analysis was performed to estimate patients' overall survival ( - Fig. 7 ). The mean survival was 163.2 days (standard deviation [SD] 72.6 days and $95 \%$ confidence interval $[\mathrm{CI}]$ of 20.98-305.42), and the median survival was 44.0 days ( $95 \% \mathrm{CI}$ of 19.00 to 68.00 ). Death was mostly caused by primary tumor disease $(n=12)$, followed by sepsis $(n=1)$ and lung embolism $(n=1)$. Two patients are still alive ( - Table 2 ). Survival analysis could not be reasonably stratified in patients with and without chemotherapy due to the small patient number. 
Table 1 Patients' characteristics

\begin{tabular}{|c|c|c|c|c|}
\hline No. & Sex & $\begin{array}{l}\text { Age } \\
\text { (year) }\end{array}$ & Cause of unsuccessful/impossible ERCP & Inoperable carcinoma \\
\hline 1 & M & 77 & Duodenal tumor stenosis & Pancreas carcinoma \\
\hline 2 & M & 66 & Gastric outlet obstruction by tumor & Pancreas carcinoma \\
\hline 3 & $\mathrm{~F}$ & 63 & Duodenal tumor stenosis & Pancreas carcinoma \\
\hline 4 & $\mathrm{~F}$ & 79 & Duodenal tumor stenosis & Pancreas carcinoma (metastasized) \\
\hline 5 & M & 77 & Duodenal tumor stenosis & Carcinoma of the duodenal papilla \\
\hline 6 & M & 80 & Status post gastrectomy & Pancreas carcinoma \\
\hline 7 & $\mathrm{~F}$ & 71 & Duodenal tumor stenosis & Duodenal carcinoma \\
\hline 8 & $\mathrm{~F}$ & 66 & $\begin{array}{l}\text { Biliodigestive anastomosis/ } \\
\text { pancreaticoduodenectomy }\end{array}$ & Pancreas carcinoma (recurrence) \\
\hline 9 & $\mathrm{~F}$ & 55 & Duodenal tumor stenosis & Duodenal carcinoma \\
\hline 10 & $\mathrm{~F}$ & 83 & Duodenal tumor stenosis/gastroenterostomy & Pancreas carcinoma (ERCP stent occlusion) \\
\hline 11 & M & 77 & $\begin{array}{l}\text { Biliodigestive anastomosis/ } \\
\text { pancreaticoduodenectomy }\end{array}$ & Distal cholangiocarcinoma (recurrence) \\
\hline 12 & $\mathrm{M}$ & 52 & Duodenal tumor stenosis & Pancreas carcinoma \\
\hline 13 & $\mathrm{M}$ & 75 & Hilar cholangiocarcinoma & Hilar cholangiocarcinoma (metastasized) \\
\hline 14 & $\mathrm{~F}$ & 80 & Difficult papilla by tumor infiltration & Pancreas carcinoma \\
\hline 15 & M & 79 & Duodenal tumor stenosis & Pancreas carcinoma (metastasized) \\
\hline 16 & M & 68 & Status post gastrectomy & Gastric cancer (recurrence) \\
\hline
\end{tabular}

Abbreviation: ERCP, endoscopic retrograde cholangiopancreatography; F, female; M, male.

\section{Discussion}

We reported an optimized method of PTBD combining ultrasound-guided bile duct puncture and percutaneous transhepatic biliary stenting by fluoroscopic and endoscopic luminal guidance as a one step-procedure in patients with malignant bile duct obstruction with good technical and clinical success rates in a small and detailed described sample size of 16 PTBDs, extracted from 116 PTBDs in our single tertiary referral center hospital. We documented just two adverse events (severity grade: mild $1 \times$ and modest: $1 \times$ ) and only one re-intervention in an observational follow-up period of 6 months.

In the case when ERCP could not have been performed due to duodenal tumor obstruction using a duodenovideoscope (outer diameter of the distal end: $13.7 \mathrm{~mm}$ ), the duodenal stenosis could still be passed by a gastrointestinal videoscope with a smaller outer diameter (5.4-9.9 mm) and a more flexible distal end. Usually, it is not possible to perform ERCP with a gastrointestinal videoscope without a forceps elevator. Therefore, we just used the endoscope (in combination with the fluoroscopic image) to visualize the papilla and to visualize the optimal percutaneous transhepatic stent placement. Besides, it is crucial for endoscopic re-interventions in the follow-up (for example, for the reopening of an occluded metal stent) that the metal stent does not stand out too much out of the papilla. In our experience, unique fluoroscopic guidance is not accurate enough for optimal metal stent implantation in relation to the papilla (data not shown). However, we observed just one stent occlusion in the follow-up in the extracted cohort of 16 PTBDs with primary stent implantation. This stent occlusion could be managed with a gastrointestinal videoscope without a forceps elevator. A further randomized study has to proof the hypothesis that the combined use of endoscopic luminal and fluoroscopic guidance increases the rate of successful endoscopic re-interventions in comparison with the unique use of fluoroscopic guidance. Since palliative tumor therapies become more and more effective, it is presumed that re-interventions of occluded metal stents will be necessary more often in the future due to longer patient survival. According to our best knowledge, this is the first publication that describes the combination of ultrasound-guided bile duct puncture and percutaneous transhepatic biliary stenting by combination of fluoroscopic and endoscopic luminal guidance as a one-step-procedure.

In three patients with altered abdominal anatomy after surgery (biliodigestive anastomosis and status post gastrectomy), stent implantation by endoscopic luminal guidance was not performed and attempted (even if it would have been possible with a single- or double-balloon endoscope). On the one hand, there is enough space for bile drainage at the distal end of the expanded metal stent in the anastomosed biliodigestive intestinal loop, and on the other hand, endoscopic luminal re-interventions are rarely successful in this situation; therefore, placement of the distal end of the metal stent was considered as less relevant. Fortunately, we observed no stent occlusion in any of the three patients in the follow-up. Balloon enteroscopeassisted endoscopic retrograde cholangiopancreatography could be used as an alternative method in this setting, but the procedure time usually is longer in comparison with 
Table 2 Ultrasound-guided PTBD procedures with primary metal stent implantation by endoscopic luminal guidance and follow-up

\begin{tabular}{|c|c|c|c|c|c|c|c|c|c|c|}
\hline No. & $\begin{array}{l}\text { Side of } \\
\text { access } \\
\text { to liver }\end{array}$ & $\begin{array}{l}\text { SEMS } \\
(\mathrm{mm})\end{array}$ & $\begin{array}{l}\text { Endoscopic } \\
\text { guidance }\end{array}$ & $\begin{array}{l}\text { Procedural } \\
\text { time }(\mathrm{m})\end{array}$ & $\begin{array}{l}\text { Radiation } \\
\text { exposure } \\
\left(\mu G y / m^{2)}\right.\end{array}$ & $\begin{array}{l}\text { Fluoroscopic } \\
\text { time (m) }\end{array}$ & $\begin{array}{l}\text { Technical } \\
\text { success }\end{array}$ & $\begin{array}{l}\text { Chemo- } \\
\text { therapy }\end{array}$ & $\begin{array}{l}\text { Survival } \\
\text { time (d) }\end{array}$ & $\begin{array}{l}\text { Cause of } \\
\text { death }\end{array}$ \\
\hline 1 & Left & $\begin{array}{l}\mathrm{nc} 10 \\
\times 100\end{array}$ & Yes & 89 & 8889 & 22,1 & Yes & No & 36 & $\begin{array}{l}\text { Primary } \\
\text { disease }\end{array}$ \\
\hline 2 & Left & $\begin{array}{l}\text { nc } 10 \\
\times 80\end{array}$ & Yes & 90 & 7164 & 22,4 & Yes & No & 35 & $\begin{array}{l}\text { Primary } \\
\text { disease }\end{array}$ \\
\hline 3 & Right & $\begin{array}{l}\text { nc } 10 \\
\times 80\end{array}$ & Yes & 105 & 14130 & 41,9 & $\begin{array}{l}\text { Yes }\left(2^{\text {nd }}\right. \\
\text { attempt) }\end{array}$ & No & 46 & $\begin{array}{l}\text { Lung } \\
\text { embolism }\end{array}$ \\
\hline 4 & Left & $\begin{array}{l}\mathrm{nc} 10 \\
\times 80\end{array}$ & Yes & 105 & 17569 & 46,0 & Yes & $\begin{array}{l}\text { Gem/ } \\
\text { Paclitaxel }\end{array}$ & 125 & $\begin{array}{l}\text { Primary } \\
\text { disease }\end{array}$ \\
\hline 5 & Left & $\begin{array}{l}\text { nc } 10 \\
\times 80\end{array}$ & Yes & 60 & 5100 & 12,4 & Yes & No & 864 & Sepsis \\
\hline 6 & Left & $\begin{array}{l}\mathrm{nc} 10 \\
\times 80\end{array}$ & Yes & 70 & 1341 & 13,6 & Yes & No & 44 & $\begin{array}{l}\text { Primary } \\
\text { disease }\end{array}$ \\
\hline 7 & Left & $\begin{array}{l}\mathrm{nc} 10 \\
\times 80\end{array}$ & Yes & 40 & 2368 & 3,0 & Yes & No & 68 & $\begin{array}{l}\text { Primary } \\
\text { disease }\end{array}$ \\
\hline 8 & Left & $\begin{array}{l}\mathrm{nc} 10 \\
\times 60\end{array}$ & No & 25 & 862 & 6,1 & Yes & No & 19 & $\begin{array}{l}\text { Primary } \\
\text { disease }\end{array}$ \\
\hline 9 & Left & $\begin{array}{l}\text { pc } 10 \\
\times 80\end{array}$ & Yes & 50 & 2428 & 13,6 & Yes & FOLFOX & 46 & $\begin{array}{l}\text { Primary } \\
\text { disease }\end{array}$ \\
\hline 10 & Right & $\begin{array}{l}\text { nc } 10 \\
\times 80\end{array}$ & Yes & 48 & 2112 & 11,2 & Yes & No & 430 & $\begin{array}{l}\text { Primary } \\
\text { disease }\end{array}$ \\
\hline 11 & Left & $\begin{array}{l}\text { nc } 10 \\
\times 80\end{array}$ & No & 67 & 7429 & 19,6 & Yes & No & 7 & $\begin{array}{l}\text { Primary } \\
\text { disease }\end{array}$ \\
\hline 12 & Left & $\begin{array}{l}\text { nc } 10 \\
\times 80\end{array}$ & Yes & 52 & 4607 & 10,3 & Yes & No & 17 & $\begin{array}{l}\text { Primary } \\
\text { disease }\end{array}$ \\
\hline 13 & Left & $\begin{array}{l}\text { nc } 8 \times \\
100\end{array}$ & Yes & 118 & 10713 & 27,0 & No & No & 25 & $\begin{array}{l}\text { Primary } \\
\text { disease }\end{array}$ \\
\hline 14 & Left & $\begin{array}{l}\mathrm{nc} 10 \\
\times 80\end{array}$ & Yes & 73 & 3747 & 29,4 & Yes & $\begin{array}{l}\text { Gem- } \\
\text { citabine } \\
\text { mono }\end{array}$ & $\begin{array}{l}342-\text { still } \\
\text { alive }\end{array}$ & \\
\hline 15 & Left & $\begin{array}{l}\mathrm{nc} 10 \\
\times 80\end{array}$ & Yes & 68 & 6383 & 14,4 & Yes & No & 39 & $\begin{array}{l}\text { Primary } \\
\text { disease }\end{array}$ \\
\hline 16 & Left & $\begin{array}{l}\text { nc } 10 \\
\times 60\end{array}$ & No & 29 & 471 & 5,1 & Yes & FLO & $\begin{array}{l}91-\text { still } \\
\text { alive }\end{array}$ & \\
\hline
\end{tabular}

Abbreviations: d, days; FLO, fluorouracil, folinic acid, oxaliplatin; FOLFOX, folinic acid, fluorouracil and oxaliplatin; m, months; nc, non covered; PTBD, percutaneous transhepatic biliary drainage; SEMS, self-expandable metal stent.

percutaneous transhepatic biliary stenting and the procedure can cause severe complications, such as perforation or pancreatitis. ${ }^{23}$

In a recent systematic review and meta-analysis about the efficacy and safety of EUS-guided biliary drainage in comparison with percutaneous biliary drainage, ${ }^{9}$ there was no difference in technical success between the two procedures, but PTBD was associated with a lower level of clinical success, a higher level of post-procedural adverse events, and a higher rate of re-interventions. ${ }^{9}$ The important question is whether PTBD was performed in an appropriate way to allow us to compare it adequately with EUS-BD. In the above-mentioned review, six completely published studies (two prospective and four retrospective) were included (-Table 3) with a PTBD case size from 12 to 51 (3-8). The post-procedural adverse event rate accounted for between 10 and 54\%. Re-intervention rate was reported in four studies and ranged from 0.8 to 1.7 (mean frequency for additional PTBDs per patient).3,4,7,8 A detailed description of the PTBD procedure was only reported in four out of six studies. ${ }^{3,5-7}$ PTBDs which were performed with ultrasound guidance had fewer adverse events (10-25\%) than PTBDs which only used fluoroscopic guidance (31-46\%). In the study from Artifon et al, ${ }^{6} 4$ of the 12 patients underwent external drainage catheter insertion before metal stent implantation. According to our experience, external drainages should be strictly avoided in PTBD because they could cause many adverse events such as bile leak, bilioma, or dislocation, and this could result in the need for further PTBD sessions. In this study, it was not reported whether 
PTBDs with external drainages caused the documented adverse events or not. In the study from Bapaye et al, ${ }^{5}$ just $12 / 26(46 \%)$ metal stents and 14/26 (54\%) external drainages were inserted, which was probably the reason for the high figure of 12 adverse events (46\%). Furthermore, PTBD without metal stent implantation is worse when compared with EUS-BD, in which metal stent implantation is performed regularly in patients with malignant bile duct obstruction. In the study from Khashab et $\mathrm{al}^{4}{ }^{4}$ it was not reported at all whether metal stents were used in PTBD or not. Furthermore, a disproportionate amount of bile leaks

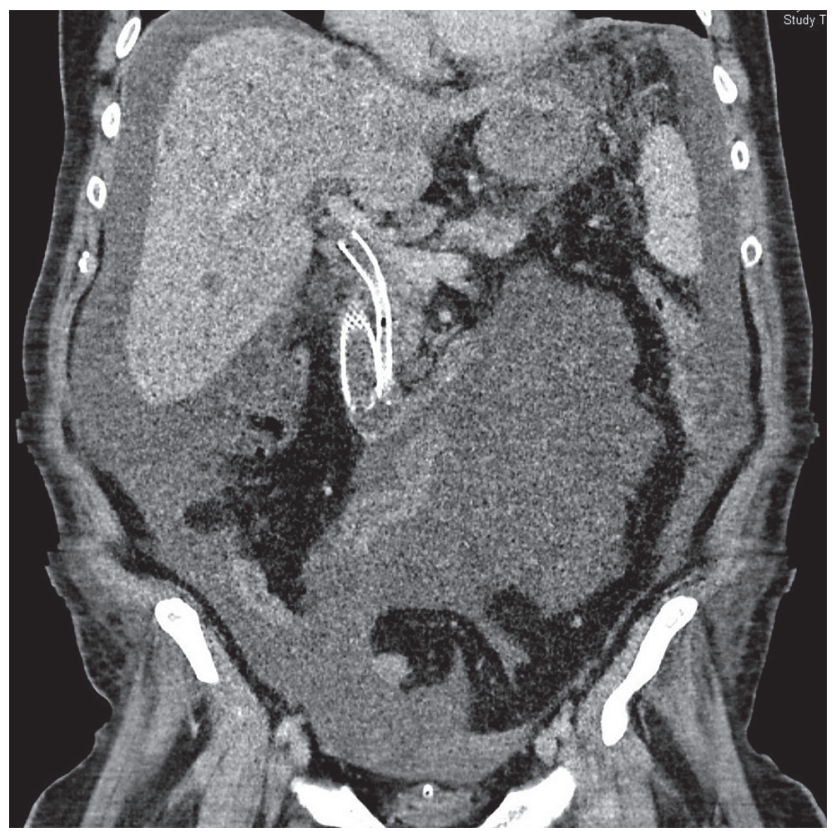

Fig. 6 CT abdomen (coronal image) in a patient with biliary ascites due to the delayed expansion of the biliary metal stent in the vicinity of a duodenal metal stent. CT, computed tomography. and a high amount of scheduled re-interventions were also reported, neither of which are necessary in a PTBD protocol as a one-step procedure. In the study from Lee et al, ${ }^{14}$ an external drainage was inserted regularly (which caused scheduled re-interventions) before metal stent insertion, and only 15 (48\%) metal stents were inserted overall. In the study from Sharaih et $a l^{8}$ it was not reported how many metal stents were inserted, and how many benign and malign diseases were mixed and not differentiated, which makes any comparison with EUS-BD very difficult. Lastly, in the study from Sportes et al, ${ }^{7}$ the external drainage was left after metal stent implantation and removed some days later when stent implantation was clinically successful. This further procedure may not be necessary when stent release is visualized by endoscopic luminal guidance as discussed above.

In conclusion, the way that we perform PTBD may have the following advantages. First, color Doppler ultrasound-guided PTBD has the advantage of cannulating the bile duct by ultrasound guidance and visualized intrahepatic vessels. Incidentally, this is how EUS-guided biliary cannulation is performed regularly. In this way, injury of intrahepatic blood vessels with severe intrahepatic bleeding or hemobilia can be better prevented. Therefore, no severe bleeding event was documented in this study, and in the study, we have already published on this topic. ${ }^{15}$ Second, we favored the access to the intrahepatic bile duct from the left side of the liver because on the right liver side, usually an intercostal access route has to be chosen which causes more adverse events such as biliary effusion or pneumothorax, as well as more patient discomfort and pain. This result corresponds with a recently published study from Liu et al, ${ }^{20}$ in which PTBD success was increased with left lobe entry (adjusted odds ratio [aOR] $=1.853,95 \% \mathrm{CI}$ $1.167,2.940$ ) and complications were significantly decreased (aOR $=0.450,95 \% \mathrm{CI} 0.263,0.769)$. Therefore, the left liver is

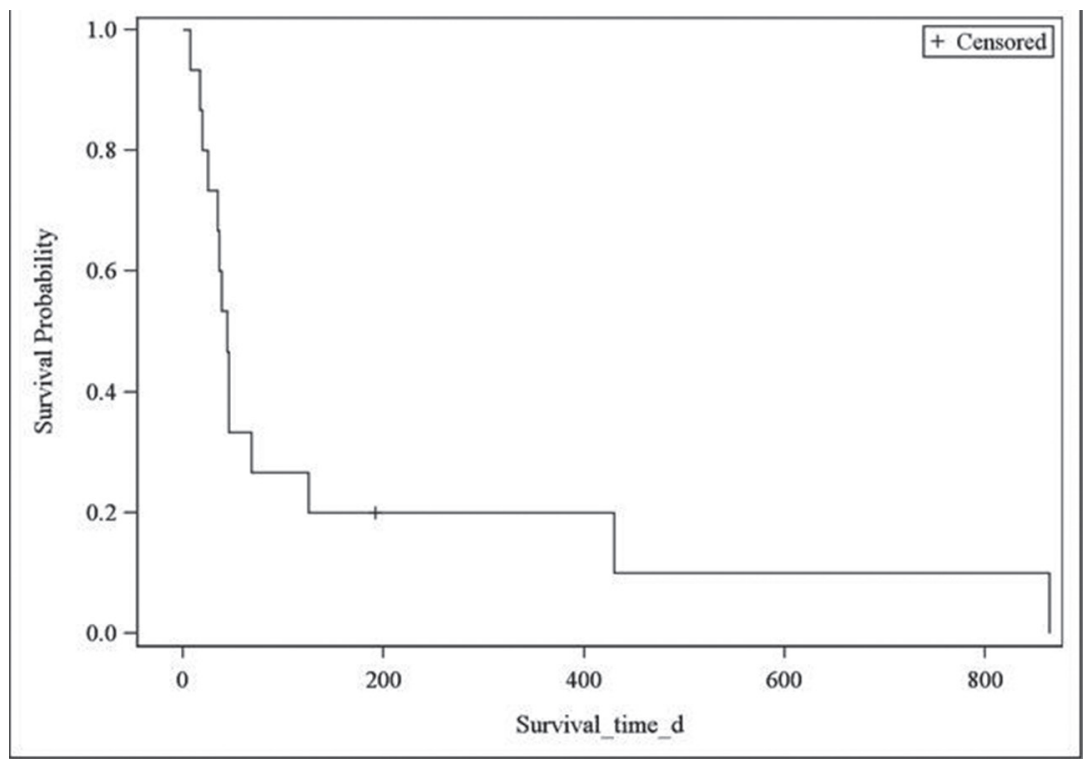

Fig. 7 Kaplan-Meier analysis on overall survival probability after PTBD with primary metal stent implantation in patients with malignant bile duct obstruction $(n=16)$. PTBD, percutaneous transhepatic biliary drainage 
Table 3 Overview on comparative studies between PTBD and EUS-BD

\begin{tabular}{|c|c|c|c|c|c|c|}
\hline $\begin{array}{l}\text { Authors } \\
\text { and year }\end{array}$ & Study type & $\begin{array}{l}\text { PTBDs } \\
\text { (n) }\end{array}$ & $\begin{array}{l}\text { Adverse } \\
\text { events (n) }\end{array}$ & $\begin{array}{l}\text { Reinterventions } \\
\text { (mean frequency) }\end{array}$ & $\begin{array}{l}\text { Method of } \\
\text { PTBD access }\end{array}$ & Special comments \\
\hline $\begin{array}{l}\text { Artifon } \\
\text { et al, } 2012^{6}\end{array}$ & Prospective & 12 & $3(25 \%)$ & Not analyzed & $\begin{array}{l}\text { Fluoroscopic } \\
\text { and ultrasound } \\
\text { guidance }\end{array}$ & $\begin{array}{l}\text { Four external drain- } \\
\text { ages before metal } \\
\text { stent insertion }\end{array}$ \\
\hline $\begin{array}{l}\text { Bapaye } \\
\text { et al, } 2013^{5}\end{array}$ & Retrospective & 26 & $12(46 \%)$ & Not analyzed & $\begin{array}{l}\text { Fluoroscopic } \\
\text { guidance }\end{array}$ & $\begin{array}{l}\text { Only } 12 / 26(46 \%) \\
\text { metal stents and } \\
14 / 26(54 \%) \text { external } \\
\text { drainages }\end{array}$ \\
\hline $\begin{array}{l}\text { Khashab } \\
\text { et al, } 2015^{4}\end{array}$ & Retrospective & 51 & $20(39 \%)$ & $0.80(n=41)$ & $\begin{array}{l}\text { No detailed } \\
\text { description }\end{array}$ & $\begin{array}{l}\text { Not reported wheth- } \\
\text { er metal stents were } \\
\text { used or not, many } \\
\text { scheduled re-inter- } \\
\text { ventions, many bile } \\
\text { leaks }(n=17)\end{array}$ \\
\hline $\begin{array}{l}\text { Sharaiha } \\
\text { et al, } 2016^{8}\end{array}$ & Retrospective & 13 & 7 (54\%) & $1.70(n=22)$ & $\begin{array}{l}\text { no detailed } \\
\text { description }\end{array}$ & $\begin{array}{l}\text { Benign and ma- } \\
\text { lignant bile duct } \\
\text { obstruction were } \\
\text { mixed, number of } \\
\text { metal stents remains } \\
\text { unclear }\end{array}$ \\
\hline $\begin{array}{l}\text { Lee et al, } \\
2016^{3}\end{array}$ & Prospective & 32 & $10(31 \%)$ & $0.93(n=29)$ & $\begin{array}{l}\text { Fluoroscopic } \\
\text { guidance }\end{array}$ & $\begin{array}{l}\text { Two-step interven- } \\
\text { tion: external drain- } \\
\text { age before metal } \\
\text { stent insertion, just } \\
15(48 \%) \text { of metal } \\
\text { stents inserted }\end{array}$ \\
\hline $\begin{array}{l}\text { Sportes } \\
\text { et al, } 2017^{7}\end{array}$ & Retrospective & 20 & $2(10 \%)$ & $1.05(n=21)$ & $\begin{array}{l}\text { Ultrasound } \\
\text { guidance }\end{array}$ & $\begin{array}{l}\text { External drain was } \\
\text { left after metal stent } \\
\text { implantation and } \\
\text { removed some days } \\
\text { later when stent } \\
\text { implantation was } \\
\text { clinically successful, } \\
\text { scheduled re-inter- } \\
\text { ventions were mixed } \\
\text { with unscheduled } \\
\text { re-interventions }\end{array}$ \\
\hline
\end{tabular}

Abbreviations: EUS-BD, endoscopic ultrasound-guided biliary drainage; PTBD, percutaneous transhepatic biliary drainage.

now our standard access side for all PTBDs in patients with infrahilar bile duct obstruction. Third, we performed PTBD with implantation of the self-expanding metal stent in the first session as a one-step procedure. This has the advantage that no further re-intervention is necessary after insertion of an external or an external/internal drainage, an outcome which can cause further adverse events such as bile duct leak along the catheter, biliary ascites, or catheter dislocation..$^{21}$ In one of our PTBD procedures, we documented biliary ascites, but this event was caused by the delayed expansion of the metals stent in the vicinity of a duodenal stent and a strong tumor infiltration of the bile duct. Fourth, we performed stent release by endoscopic luminal guidance. In this way, the positioning and the correct expansion of the distal tip of the metal stent can be observed directly in comparison with the stent release, which is performed by fluoroscopic guidance alone. ${ }^{22}$ In this strategy, some investigators leave behind an external drainage in the bile duct until the clinical success of the procedure can be documented in the subsequent days (as has been described above). This is not necessary when stent release is immediately controlled endoscopically. Fifth, PTBD with antegrade stenting (metal stent through tumor stenosis) is able to restore the "natural" bile duct route in comparison with transluminal stenting in EUS-BD with EUS-guided hepatogastrostomy or EUS-guided choledochoduodenostomy. Furthermore, these techniques can cause other severe adverse events such as stent migration into the abdominal cave or pneumoperitoneum. But this question has to be clarified in further studies which compare PTBD with EUS-BD as equivalent methods in well-defined comparable diseases. Sixth, it should be mentioned that the technique of ultrasound-guided peripheral portal vein-oriented non-dilated bile duct puncture can be a further valuable method to improve bile duct access and to avoid bleeding complications. ${ }^{24}$

The limitations of our study include the following-the retrospective character, the single-center experience, and the extracted small sample size.

The further study should be a prospective, non-randomized multicenter study (e.g., one in which each center performs bile duct intervention with its best practice) as a 
comparison between ultrasound-guided PTBD with primary metal stent implantation with endoscopic luminal guidance on the one hand, and EUS-BD on the other hand (EUS-guided antegrade, transpapillary drainage, EUS-guided transhepatic drainage and EUS-guided choledochal drainage) in an adequate number of cases.

\section{Conclusion}

Percutaneous biliary drainage with ultrasound-guided ductal puncture and primary metal implantation by endoscopic luminal guidance had a good technical and clinical success rate in patients with malignant biliary obstruction in our selected patient cohort. Adverse events were rare, and re-intervention rate was very low. A prospective, non-randomized, comparative multicenter study with ultrasound-guided PTBD with primary metal stent implantation by endoscopic luminal guidance and EUS-BD in patients with malignant extrahepatic bile duct obstruction should be initiated to demonstrate relevant statistical differences (or non-inferiority), with a particular focus on success, adverse events, and the re-intervention rate.

\section{Institutional Review Board Statement}

This study was reviewed and approved by the ethics committee of the Mannheim University Hospital on February 02, 2018 (2018-815R-MA).

\section{Biostatistics Statement}

The statistical methods and results were reviewed and verified by a member of the Medical statistics, Biomathmatics and Information Processing of Mannheim University Hospital.

\section{Conflicts of Interest}

All authors declare no conflicts of interest related to this article.

\section{References}

1 Speer AG, Cotton PB, Russell RC, et al. Randomised trial of endoscopic versus percutaneous stent insertion in malignant obstructive jaundice. Lancet 1987;2(8550):57-62

2 Giovannini M, Moutardier V, Pesenti C, Bories E, Lelong B, Delpero JR. Endoscopic ultrasound-guided bilioduodenal anastomosis: a new technique for biliary drainage. Endoscopy 2001;33(10):898-900

3 Lee TH, Choi JH, Park H, et al. Similar efficacies of endoscopic ultrasound-guided transmural and percutaneous drainage for malignant distal biliary obstruction. Clin Gastroenterol Hepatol 2016;14(7):1011-1019.e3

4 Khashab MA, Valeshabad AK, Afghani E, et al. A comparative evaluation of EUS-guided biliary drainage and percutaneous drainage in patients with distal malignant biliary obstruction and failed ERCP. Dig Dis Sci 2015;60(2):557-565

5 Bapaye A, Dubale N, Aher A. Comparison of endosonography-guided vs. percutaneous biliary stenting when papilla is inaccessible for ERCP. United European Gastroenterol J 2013;1(4):285-293

6 Artifon EL, Aparicio D, Paione JB, et al. Biliary drainage in patients with unresectable, malignant obstruction where ERCP fails: endoscopic ultrasonography-guided choledochoduodenostomy versus percutaneous drainage. J Clin Gastroenterol 2012;46(9):768-774

7 Sportes A, Camus M, Greget M, et al. Endoscopic ultrasound-guided hepaticogastrostomy versus percutaneous transhepatic drainage for malignant biliary obstruction after failed endoscopic retrograde cholangiopancreatography: a retrospective expertise-based study from two centers. Therap Adv Gastroenterol 2017;10(6):483-493

8 Sharaiha RZ, Kumta NA, Desai AP, et al. Endoscopic ultrasound-guided biliary drainage versus percutaneous transhepatic biliary drainage: predictors of successful outcome in patients who fail endoscopic retrograde cholangiopancreatography. Surg Endosc 2016;30(12):5500-5505

9 Sharaiha RZ, Khan MA, Kamal F, et al. Efficacy and safety of EUS-guided biliary drainage in comparison with percutaneous biliary drainage when ERCP fails: a systematic review and meta-analysis. Gastrointest Endosc 2017;85(5):904-914

10 Saad WE. Transhepatic techniques for accessing the biliary tract. Tech Vasc Interv Radiol 2008;11(1):21-42

11 Wimmer B, Hauenstein KH, Kauffmann G, Friedburg H. [Sonography for percutaneous biliary drainage (author's transl)] RoFo Fortschr Geb Rontgenstr Nuklearmed 1981;135(4):466-470

12 Sukigara M, Taguchi Y, Watanabe T, Koshizuka S, Koyama I, Omoto R. Percutaneous transhepatic biliary drainage guided by color Doppler echography. Abdom Imaging 1994 19(2):147-149

13 Koito K, Namieno T, Nagakawa T, Morita K. Percutaneous transhepatic biliary drainage using color Doppler ultrasonography. J Ultrasound Med 1996;15(3):203-206

14 Lee W, Kim GC, Kim JY, et al. Ultrasound and fluoroscopy guided percutaneous transhepatic biliary drainage in patients with nondilated bile ducts. Abdom Imaging 2008;33(5):555-559

15 Schmitz D, Grosse A, Hallscheidt P, Roseneck A, Niemeyer J, Rudi J. Color Doppler ultrasound-guided PTBD with and without metal stent implantation by endoscopic control: prospective success and early adverse event rates. Z Gastroenterol 2015;53(11):1255-1260

16 Tamada K, Tomiyama T, Wada S, et al. Catheter dislodgement of percutaneous transhepatic biliary drainage: identification of role of puncture sites and catheter sheath. Abdom Imaging 2000;25(6):587-591

17 Liu YS, Lin CY, Chuang MT, Tsai YS, Wang CK, Ou MC. Success and complications of percutaneous transhepatic biliary drainage are influenced by liver entry segment and level of catheter placement. Abdom Radiol (NY) 2018;43(3):713-722

18 van Delden OM, Laméris JS. Percutaneous drainage and stenting for palliation of malignant bile duct obstruction. Eur Radiol 2008;18(3):448-456

19 https://www.wma.net/policies-post/wma-declaration-of-helsinki-ethical-principles-for-medical-research-involving-human-subjects

20 Cotton PB, Eisen GM, Aabakken L, et al. A lexicon for endoscopic adverse events: report of an ASGE workshop. Gastrointest Endosc 2010;71(3):446-454

21 Nennstiel S, Weber A, Frick G, et al. Drainage-related complications in percutaneous transhepatic biliary drainage: an analysis over 10 years. J Clin Gastroenterol 2015;49(9):764-770

22 Covey AM, Brown KT. Percutaneous transhepatic biliary drainage. Tech Vasc Interv Radiol 2008;11(1):14-20

23 Yamauchi $\mathrm{H}$, Kida $\mathrm{M}$, Imaizumi $\mathrm{H}$, et al. Innovations and techniques for balloon-enteroscope-assisted endoscopic retrograde cholangiopancreatography in patients with altered gastrointestinal anatomy. World J Gastroenterol 2015;21(21):6460-6469

24 Shimizu H, Kato A, Takayashiki T, et al. Peripheral portal vein-oriented non-dilated bile duct puncture for percutaneous transhepatic biliary drainage. World J Gastroenterol 2015;21(44):12628-12634 